\title{
Sieve tube structural variation in Austrobaileya scandens and its significance for lianescence
}

\author{
Juan Losada ${ }^{1}$, Zhe $\mathrm{He}^{2}$, and Noel Holbrook ${ }^{2}$ \\ ${ }^{1} \mathrm{CSIC}$ \\ ${ }^{2}$ Harvard University
}

October 29, 2021

\begin{abstract}
Lianas combine large leaf areas with slender stems, features that require an efficient vascular system. The only extant member of the Austrobaileyaceae is an endemic twining liana of the tropical Australian forests with well-known xylem hydraulics, but the vascular phloem continuum aboveground remains understudied. Microscopy analysis across leaf veins and stems of A. scandens revealed a low foliar xylem to phloem ratio, with isodiametric vascular elements along the midrib, but tapered across vein orders. Small sieve plate pore radii increased from $0.08 \mu \mathrm{m}$ in minor veins to $0.12 \mu \mathrm{m}$ in the petiole, but only to $0.20 \mu \mathrm{m}$ at the stem base, tens of meters away. In searcher branches, phloem conduits contained a pectin-rich wall and simple plates, whereas in twinning stems, conduits connected through highly-angled-densely populated sieve plates. Twisted and elongated stems of A. scandens display a high hydraulic resistance of phloem conduits, which decreases from leaves to stems, efficiently delivering photoassimilate from sources under Münch predictions. Sink strength of a continuously growing canopy might be stronger than in self-supporting understory plants, favoring resource allocation to aerial organs in angiosperms that colonized the vertical niche.
\end{abstract}

\section{Article title:}

Sieve tube structural variation in Austrobaileya scandens and its significance for lianescence

\section{Short running::}

Phloem of lianas

Juan M. Losada ${ }^{1,2,3^{*}}$

Zhe $\mathrm{He}^{2,3}$

N. Michele Holbrook ${ }^{2,3}$

${ }^{1}$ Institute for Mediterranean and Subtropical Horticulture 'La Mayora' - CSIC - UMA, Avda. Dr. Wienberg s/n, Málaga, 29750, Spain.

${ }^{2}$ Department of Organismic and Evolutionary Biology, Harvard University, 16 Divinity Avenue, Cambridge, MA, 02138, USA.

${ }^{3}$ Arnold Arboretum of Harvard University, 1300 Centre St., Boston, MA, 02130, USA.

*Author for correspondence:

Phone: $+34(689) 258686$

E-mail:juan.losada.r@gmail.com 


\section{SUMMARY}

Lianas combine large leaf areas with slender stems, features that require an efficient vascular system. The only extant member of the Austrobaileyaceae is an endemic twining liana of the tropical Australian forests with well-known xylem hydraulics, but the vascular phloem continuum aboveground remains understudied.

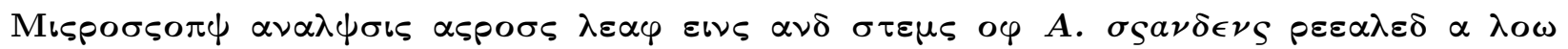

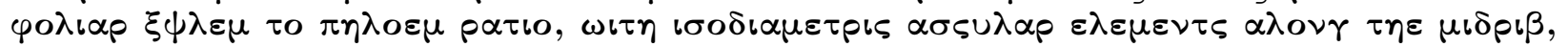

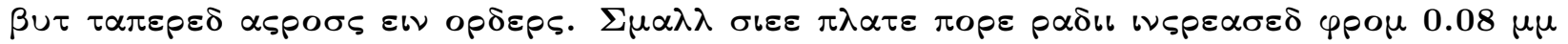

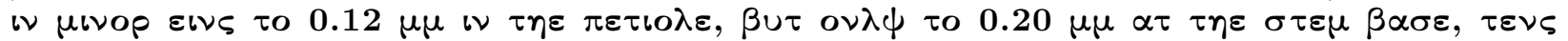

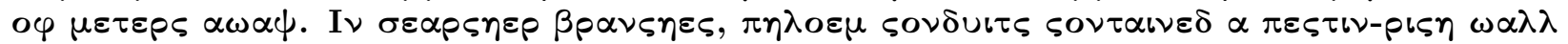

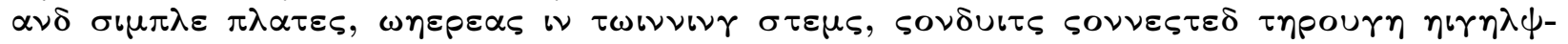

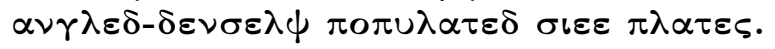

Twisted and elongated stems of $A$. scandens display a high hydraulic resistance of phloem conduits, which decreases from leaves to stems, efficiently delivering photoassimilate from sources under Münch predictions. Sink strength of a continuously growing canopy might be stronger than in self-supporting understory plants, favoring resource allocation to aerial organs in angiosperms that colonized the vertical niche.

Keywork index: Austrobaileya scandens, lianescence, pectins, phloem, sieve-tubes, vessels, xylem.

\section{INTRODUCTION}

Lianas constitute about $40 \%$ of the woody individuals in tropical forests and make an outsize contribution to forest productivity and response to disturbance (Gerwing \& Farias, 2000; Schnitzer et al., 2012) as a result of their ability to elevate a dense leaf canopy tens of meters aboveground with a minimal investment in self-support (Darwin, 1868; Baillaud, 1962). Anatomical features that allow lianas to meet the evaporative demands of their leaves despite having slender stems include large diameter xylem vessels, and thus greater hydraulic efficiency, compared with co-occurring trees and shrubs (Carlquist, 1991; Ewers et al., 1991; Isnard et al., 2003; Isnard \& Silk, 2009; Wyka et al., 2013; Chen et al., 2014; Pace et al., 2015, 2018; Chery et al., 2020). The allometrical demands of the climbing habit might be expected to extend to the phloem. Yet, the long-distance effectiveness of carbohydrate transport remains poorly documented in lianas, due to the scarce information on the intersection between the vascular structure of the phloem and lianescence.

Previous anatomical descriptions of the stems of large-bodied vines belonging to Loganiaceae, Malpighiaceae, Bignoniaceae, Fabaceae or Sapindaceae emphasize novel topologies with distinctive cambia: anomalous phloem architectures that evolved with the scandent habit and represent traits associated with higher flexibility and resilience to damage (Ewers et al., 1991; Fisher \& Blanco, 2014; Moya et al., 2017; Pace et al., 2011; 2015; 2018; Chery et al., 2020). Structural variation of sieve tube elements in relation to axial transport, however, has only been explored in the long and slender stems of Ipomoea nil(Knoblauch et al., 2016), which showed that while sieve tube geometry varied little axially, sieve pores connecting conduits increased in diameter from the top to the base of the stem, in agreement with the pressure-flow hypothesis developed by Münch in 1930 (Knoblauch et al., 2016). In other woody life forms such as trees and shrubs, axial scaling of sieve tubes includes structural variation of phloem conduit diameter and length, the size of pores, and the number of sieve plates, all contributing to a more efficient transport at long distances (Liesche et al., 2017; Savage et al., 2017; Losada \& Holbrook, 2019; Clerx et al., 2020; Barceló-Anguiano et al., 2021a,b).

Austrobaileya scandens is a large-bodied and long-lived liana native to Queensland (Australia), which reaches more than $15 \mathrm{~m}$ aboveground by twining around trees as its only support (Bailey \& Swamy 1949). A. scandens exhibits low photosynthetic rates and a slow stomatal response to drops in environmental humidity (Feild et al., 2003a,b; Feild \& Arens, 2005, 2007; Feild \& Wilson, 2012; Barral et al., 2013). Anatomically, the stems of A. scandens display wide xylem vessels (Carlquist, 2001) and a secondary phloem with extremely angled compound sieve plates (Behnke, 1986). This sieve tube morphology, which resembles the phloem of 
gymnosperms, drove early speculations on a possible transitional tissue toward the 'pipe-like' sieve tubes of most angiosperms (Bailey \& Swamy, 1949; Srivastava, 1970; Behnke, 1986). An alternative perspective is that angled plates compensate for small pore diameters, or that the peculiar morphology of the secondary phloem of Austrobaileya possibly relates to maintaining the functional demands of the phloem as climbing stems undergo mechanical deformation. To better understand vascular transport in large-bodied lianas, we studied the phloem of leaves and stems, so far missing in this species. The main goal of this study was to understand the structure of the phloem in relation to 1) axial transport of carbohydrates from the sites of photosynthesis through the slender stems; 2) mechanical demands of climbing.

\section{MATERIALS AND METHODS}

\subsection{Plant material}

We used the germplasm resources of the Arnold Arboretum of Harvard University, which includes greenhousegrown Austrobaileya scandens plants ranging in age from 20 to 25 years old. The leaf area of seven terminal branches from different plants was measured by photographing each opposite leaf pair from the branch tip to the seventh node (total $n=84$ nodes), above which leaves reached the maximum size.

\subsection{Leaf anatomy}

Five mature leaves were used to determine the area occupied by the vascular elements of the leaf midrib: consecutive hand transverse sections were cut with a micro scalpel at three different positions in the leaves: the petiole, the mid part of mid vein, and about $2 \mathrm{~cm}$ back from leaf tip. Each section was stained with $0.1 \%$ w/v aniline blue in $\mathrm{PO}_{4} \mathrm{~K}_{3}$ (pH 10) (Linskens \& Esser, 1957), observed with a Zeiss Axiophot epifluorescent microscope using the DAPI narrow filter band (excitation $365 \mathrm{~nm}$, bandpass $12 \mathrm{~nm}$; dichroic mirror FT $395 \mathrm{~nm}$; barrier filter LP397 nm), and photographed with an AxioCam 512 Color linked to the AxioVision software (Zeiss, Oberkoche, Germany). The cross-sectional area of xylem and phloem was measured (totaling 45 measures for each tissue) and, for the 27 cross sections in which all vascular elements were visible, the number of vascular elements in each tissue were counted

Five additional leaves were selected for measurements of individual sieve tubes and xylem vessels. Longitudinal sections of the petiole, midrib, second, third, and fourth order veins were obtained with a scalpel, placed in a solution containing acetic acid: hydrogen peroxide $1: 1 \mathrm{v} / \mathrm{v}$, left incubating at $60^{\circ} \mathrm{C}$ for two days, and then mounted onto glass slides for microscopy observation and image acquisition ( $\mathrm{n}>250$ total vessel elements measured). Similar areas were used to obtain fresh longitudinal sections (less than $1 \mathrm{~mm}$ thick), mounted onto slides, stained with $0.1 \%$ aniline blue, counterstained with calcofluor white for cellulose (Hughes \& McCully, 1975), photographed and measured (at least 35 sieve tubes per vein order, $\mathrm{n}=250$ ).

\subsection{Stem anatomy}

Branches were classified according to both diameter and stiffness (see Figure 1): $<2 \mathrm{~mm}$ (primary growth, flexible), $<2 \mathrm{~mm}$ (stiff and twisted around a support), 6-10 $\mathrm{mm}$ (green shoots with secondary growth), 11-15 mm (stems at the base of the vine with highly twisted-irregular bark). First, we evaluated the general anatomy of the stems in transverse sections at the top three axial locations (the widest stems could not be cut transversely to preserve the plants): flexible searchers ( $2 \mathrm{~mm}$ diameter), stiff thin branches ( $2 \mathrm{~mm}$ diameter), and mature stems (6-10mm diameter). Stem material was maintained in $1 \mathrm{X}$ Tris-buffered saline (TBS), sectioned transversally at $50 \mu \mathrm{m}$ with a Reichert-Jung Hn-40 sliding microtome (Austria), mounted onto glass slides, and stained with aniline blue that binds to callose of the sieve tubes, or with $0.1 \%$ of acridine orange in TBS buffer, which yields fluorescence of the lignified tissues (Robertson et al., 1992). To sample the phloem tissue, the external side of stems containing the bark were extracted with a sharp knife at the different positions described above, kept in buffer, sectioned longitudinally with a microscalpel, and stained with aniline blue. We measured the length and width of at least 30 sieve tubes per sampling location (total $n=107$ ), and the number of sieve areas per compound plate (total $n=45$ ).

\subsection{Scanning electron microscopy}


To evaluate the size of pores that make up the sieve plates, samples of all leaf veins and stem axial areas (see above description) were cut, frozen in liquid nitrogen, and transferred to super-chilled ethanol, prior to being sectioned in different angles with respect to the main axis with the goal of obtaining sections aligned with the highly angled sieve plates. These sections were incubated within a mixture of $0.1 \% \mathrm{w} / \mathrm{v}$ proteinase $\mathrm{K}$ dissolved in $50 \mathrm{mM}$ Tris- $\mathrm{HCl}$ buffer, $1.5 \mathrm{mM} \mathrm{Ca}^{2+}$ acetate and $8 \%$ Triton $\mathrm{X}-100, \mathrm{pH} 8.0$ (Mullendore et al., 2010), in a water bath at $60^{\circ} \mathrm{C}$ for 2 weeks. After rinsing with ethanol once, and with distilled water thrice, the sections were incubated with a $1 \% \mathrm{w} / \mathrm{v}$ aqueous solution of $\alpha$-amylase for 2 days at $60^{\circ} \mathrm{C}$, then rinsed thrice in water and finally freeze-dried for $24 \mathrm{~h}$ with a Freeze Dyer (Labconco Freeze Dry System). Samples were then mounted on SEM studs and sputter coated with gold-palladium using a Denton Vacuum Desk II Sputter Coater for $180 \mathrm{~s}$ at $20 \mathrm{~V}$ and $6.67 \mathrm{~Pa}$. Samples were imaged with a JEOL-6010LV scanning electron microscopy (SEM) (JEOL, Peabody, MA, USA), using high vacuum and an accelerating voltage of 10-15 kV. The size of sieve pores, of sieve areas, and pore density were measured. Although sieve pore radius was measured for each vein order, due to the small size of the sieve plates within higher order veins, the preservation of intact sieve plates was poor. As a result, we were only able to determine sieve plate size and pore density for the midrib $(n=5)$. The total number of pores measured was large $(n=105$ for petiole; $n=262$ for primary vein; $n=84$ for minor vein orders). In the thinnest stems, the stiffness of the external fiber layer, along with the fragility of the sieve tubes, limited preservation -and thus visualization- of the pores, relative to the base of the stem, where preservation was much better and resulted in $n=600$ pores measured.

\subsection{Phloem sap velocity in Austrobaileya scandens}

Phloem transport velocity was measured by tracking the movement of the fluorescent dye esculin (reviewed by Knoblauch et al., 2015) in the secondary veins of a five-year-old vine at 11:00 h for several days. A young plant (five years approximately) with fully formed leaves, was watered to saturation, and then one of the long branches immobilized on the microscope stage, with the abaxial surface exposed upward. A $50 \mu \mathrm{L}$ droplet of $5 \mathrm{mM}$ aqueous esculin mixture, combined with $0.1 \%$ of the SilEnergy surfactant (RedRiver Specialties, Shreveport, LA, USA), was applied with a micropipette to the junction of the second with minor order veins (adapted from Jensen et al., 2011, Savage et al., 2013). To allow better permeabilization of the dye, the tip of the pipette was used to slightly abrade the thick cuticle, and a small window was opened, and was covered with the liquid during the experiment to prevent desiccation. To track the movement of the dye, we used a portable Stereo Microscope Fluorescence Adapter with 510-540 nm excitation wavelength, and a long pass 405 UV nm filter band (NIGHTSEA, Lexington, MA, USA). Time-lapse images were obtained every $10 \mathrm{~s}$ for $30 \mathrm{~min}$ with a Zeiss v12 dissecting microscope using the $0.63 \times$ PlanApo objective and an AxioCam 512 Color camera connected to the AxioVision software. Despite multiple attempts, the movement of the dye could only be observed in two leaves. In both cases, fluorescence increased gradually downstream the vein a few minutes after the dye was applied. Velocity was measured by thresholding the images (Hue 119-188; Saturation: 97-255; Brightness: 0-255nm), cleaning the dark outliers within 2 pixels' radius, and then calculating the time elapsed by pixel accumulation two centimeters away from the area where the dye was applied $(\mathrm{n}=2)$.

\subsection{Immunolocalization of a branched pectin epitope}

Immunolocalization of branched 1-4 galactan with the LM26 monoclonal antibody (PlantProbes, Leeds, UK), was performed in the searcher stems, but not in twining stems, because they were much stiffer and embedded poorly or when embedded were difficult to section. Segments of $0.5 \mathrm{~cm}$ from flexible branches were fixed with $4 \% \mathrm{w} / \mathrm{v}$ acrolein (Polysciences, Warrington, PA, USA) in a modified piperazine-N, N'-bis (2-ethanesulfonic acid) (PIPES) buffer adjusted to $\mathrm{pH}$ 6.8 (50 mM PIPES and 1mM $\mathrm{MgSO}_{4}$ from BDH, London, UK; and 5mM EGTA) for $24 \mathrm{~h}$, then washed and dehydrated through a series of increasing aqueous acetone concentrations, one hour each: $10 \%, 30 \%, 50 \%, 70 \%, 90 \%, 100 \%$. After that, they were incubated in a solution containing the Technovit 8100 for two weeks, and then hardened in anoxic conditions at $4 \mathrm{oC}$. Longitudinal and transverse $4 \mu \mathrm{m}$ sections were obtained with a Leica EM UC7 ultramicrotome (Leica Microsystems, Wetzlar, GE), mounted onto superfrost slides, and then used for immunolocalization. Preincubation with $5 \%$ bovine albumin serum (BSA), and three washes in 1XPBS, were followed by incubation 
with the LM26 monoclonal antibody for $1 \mathrm{~h}$. After washing the primary antibody with PBS, an anti-rat alexa488 secondary antibody, with a fluorescein isothianate marker-FITC was applied for $1 \mathrm{~h}$. Samples were then washed and observed with a Leica DM2500 microscope equipped with epifluorescence and a Leica DM600 camera, combining the 405 filter for autofluorescence with the 488 filter for the specific signal of the FITC.

\subsection{Image analysis and statistics}

The transverse areas of the leaf vascular tissues were manually outlined, individual tube number counts and length/width measurements evaluated on images with the Image J 1.51d software (National Institutes of Health, Bethesda, MD, USA). Individual images from stem cross sections were aligned and merged into a composite image with the Photoshop software (Adobe Systems, Newton, MA, USA).

Averages from geometrical evaluations were compared using a one-way ANOVA and the post hoc Tukey test at a $p<0.05$, using the SPSS software for statistics.

\section{RESULTS}

\subsection{General anatomy of Austrobaileya scandens}

A. scandens are evergreen vines with long stems with opposite leaves and branches (Figure 1a,b; see also Bailey \& Swamy, 1949; Metcalfe, 1987; Feild et al., 2003b). The self-supported young apical branches are cylindrical, flexible, and about $2 \mathrm{~mm}$ diameter (Figure 1c). These young stems harden around $10 \mathrm{~cm}$ back from the tip and acquire an elliptical shape, coincident with their coiling around a solid support (Figure 1d). Despite the minimal variation of branch diameter, leaves expand exponentially along the coiled stems, reaching a maximum area at the seventh and older nodes, thus forming thick leaf canopy (Figure 1e).

\subsection{Vascular geometry in the leaves of Austrobaileya scandens}

Mature leaves of $A$. scandens (Figure 2a) are coriaceous, with a short petiole and an entire lamina. The vasculature of the petiole displayed as adaxial xylem tissue composed mainly of squared tracheids, and abaxial phloem composed of sieve tubes (identified by the presence of callose), rays, and parenchymatous tissue (Figure 2b). While fiber caps were lacking in the petiole, a massive protective perivascular fiber cap proliferated in the midrib (Figure 2c-e). The cross-sectional areas of both the xylem and the phloem were greatest in the petiole and narrowed linearly toward the tip of the major vein $\left[x y l e m: y=-0.05 x+0.20\left(\mathrm{~mm}^{2}\right)\right.$, phloem: $\left.y=-0.04 x+0.15\left(\mathrm{~mm}^{2}\right)\right]$. Strikingly, conduit diameter of both phloem and xylem were invariant along the midrib, but the number of conduits decreased by a factor of 2.6 from the petiole to the midrib tip.

Xylem and phloem conduits varied in size across vein hierarchies (Figure 3a), gradually decreasing in size from major to minor veins, except in the petiole, where tracheids were shorter and narrower than those of the midrib (Figure 3b). Although sieve tube elements were also shorter in the petiole, they were larger in diameter with respect to midrib (Fig. 3C). Sieve plate pore radii varied from $0.12 \mu \mathrm{m}( \pm 0.007 \mathrm{SE})$ in the petiole to less than $0.08 \mu \mathrm{m}( \pm 0.0006 \mathrm{SE})$ in the minor veins (Figure S1). Functionally, foliar phloem architecture correlated with a low bulk velocity of the mobile dye tracer esculin hydrate in vivo (Fig. 4; Video S1), revealing an average rate of $11 \mu \mathrm{m} \mathrm{s}^{-1}$ in the second order veins $(\mathrm{n}=2)$.

\subsection{Ontogeny of the phloem in the stems of Austrobaileya scandens}

Cross sections of stems at different axial positions revealed ontogenetic differences in the eustele, which correlated with stem mechanical properties. In the flexible searcher stems, a large pith was surrounded by discontinuous primary xylem traces consisting of only a few tracheids (Figure 5a), but a more continuous phloem layer (Figure 5b). Twining correlated with a sharp increase in the stiffness due to lignification of the pith and the development of an extra phloem pericyclic fiber layer (Figure 5c). In wider stems (the ones that traverse longest distances), the central pith constituted the largest fraction of the cross-sectional area, and the axial secondary phloem displayed a lobed morphology (Figure 5d-e), with sieve tubes closer to the vascular cambium and separated from the pericyclic fibers by parenchyma (Figure 5f). 
In line with the demands for climbing and the need for flexible searcher branches, a galacturonan-rich pectic epitope, previously related to the flexibility of sieve tubes (Torode et al., 2018), localized in the sieve tube walls of the searcher, flexible stems of $A$. scandens (Figure 6; note that we could not perform immunolocalization in the secondary phloem due to poor preservation of the twining stems). Different cell morphologies compose the stems in cross section (Figure 6a), but signal from this epitope specifically showed the scattered distribution of sieve tubes (Figure 6b,c). Upon closer inspection, the signal of the antibody corresponded with the areas of the sieve tubes between the plasma membrane and the cell walls (Figure $6 \mathrm{~d}-\mathrm{f})$. In longitudinal section, the epitope was helpful distinguishing sieve tubes from other phloem cell types (Figure 6g), which highlighted their longitudinal silhouette (Figure 6h-i), showing slightly tangential sieve plate connections (Figure 6j-1).

In the stems supported by twining, and concomitant with leaf expansion, the morphology of the sieve elements varied, gradually increasing the number of sieve plate connections at the end of the conduits (Figure 7a,b). In the thickest stems, sieve elements had extremely angled tangential connections with a great proportion of the tubes covered by sieve areas (Figure $7 \mathrm{~b}, \mathrm{c})$. Numerous small pores $(0.20 \mu \mathrm{m}$ on average, $\mathrm{n}=600)$, whose radius was similar to those of the leaf petioles, populated the sieve areas (Figure 7c,d; Behnke, 1986). In addition to morphology, sieve conduit dimensions increased from thinner to thicker stems, but their length was shorter at the base of the vine (Figure 7e).

\subsection{Phloem hydraulic resistance from leaves to stems of Austrobaileya scandens}

Anatomical data (average sieve tube radii, and pore radii/length at each location along the transport pathway in both leaves and stems) was used to estimate phloem hydraulic resistance, supposing a continuous pipe-like cylindrical tubing system formed by sieve elements connected in series, as modelled previously for vines and trees (Knoblauch et al., 2016; Savage et al., 2017). The Hagen-Poiseuille equation was the reference to understand the axial resistance of the sieve tube. Due to the difficulty of measuring the actual length of the twisted stems, we calculated the total resistance per tube length $\left(\mathrm{Pa} \mathrm{s} \mathrm{m}^{-4}\right)$ at the defined axial positions along the transport path from leaves to the base of the stem. The poor preservation the thinner twining stems allowed only a few measurements of pore size, which revealed an average radius of $0.19 \mu \mathrm{m}$, but this was quite similar to the pore radius at the base of the stem $(0.20 \mu \mathrm{m})$, where preservation was much better and resulted in $n=600$ pores measured. The following assumptions were made for calculations of the hydraulic resistance: (1) sieve areas and pore density were equal to the midrib value for higher vein orders; (2) pore size at the tip of the stems were similar to those measured at the vine base. The latter assumption is very conservative, and likely underestimates the resistance of the upper stem, given that previous reports showed smaller pore sizes at the tips of vine stems compared with their base (see Knoblauch et al., 2016). Sieve tube resistance varied about one and a half orders of magnitude from the branch tips to the base of the stems. Compared with trees of similar height, the top of the vine displayed similar sieve tube resistance, but this resistance dropped more moderately than in trees, resulting in two orders of magnitude higher resistance of $A$. scandens vines at ground level (Savage et al., 2017; Losada \& Holbrook, 2019; Clerx et al., 2020). The small pore radii of sieve plates were a major factor contributing to this high resistance (Figure 8), although compensated by an increasing number of sieve plates from top to bottom, thus overcoming resistance penalties associated with length. Monotonic decrease of axial resistance due to axial conduit structural variation encounters an exception at the base of the vine, where conduits were shorter.

\section{DISCUSSION}

\subsection{Phloem ontogeny and lianescence}

During stem ontogeny, lianas that rely exclusively on twining for climbing, such as A. scandens, transition abruptly from self-supporting branches, known as searchers, to stiffer ones that grow in close contact with a solid support. In A. scandens, the photosynthetic, non-lignified searcher branches contain more phloem than xylem tissue, likely because the immature leaves have little demands of water, but a significant need of carbohydrates. This limited xylem implies that pith turgor might be the major contributor to the mechanical stability of searcher branches, as reported in other twining vines (Isnard \& Silk, 2009). Morphologically, 
the tube-like primary sieve elements that dominated the vasculature of searchers suggested lack of lateral transport, but directional sap flow toward growing branch tips. Chemically, sieve tube walls of searcher stems were composed of a galacturonan-rich pectin, which has been described in a handful of species such as in leaves of Beta vulgaris (Torode et al., 2018), or in the seasonally renovated sieve tubes of Populus(Ray \& Savage, 2020). These previous works strongly emphasized that the chemistry of the cell walls connect with mechanics of the sieve tube wall (Torode et al., 2018). Thus, this wall related epitope may contribute to the flexibility of searcher branches, and it may also be present in sieve tubes in the secondary phloem. Nevertheless, its presence in the primary sieve tubes of $A$. scandens demonstrates that this distinctive pectin is found in the sieve tubes of angiosperms with different life histories, growth habits, and phylogenetic backgrounds.

Despite the conservation of diameter in rigid twining stems, leaf area increased and reached full expansion. Basipetally, the phloem in the twining stems acquired a lobed topology, and the sieve tubes an increasing number of plate connections, features that suggest an increase in transport efficiency under torsion. In fact, the complex division patterns (i.e. tangential longitudinal) of the secondary phloem of $A$. scandens were evaluated in detail about 50 years ago (Srivastava, 1970), and differed from axial longitudinal divisions observed in other woody angiosperms, suggesting a correlation with the helical gyres of the lianoid growth habit. In line with these observations, we further noticed that, in areas of high rotation at the base of the stems, the sieve tube elements were shorter (Silk \& Holbrook, 2005), reinforcing the idea that the vascular cambium activity is influenced by the mechanics of lianoid stems (Pace et al., 2015, 2018). How this mechanical (un)stability affects function has been studied for the lianoid xylem, which enhances hydraulic efficiency through more volumetric vessels despite the strong torsional pressures such as twisting and bending (Putz \& Holbrook, 1992; Gentry, 1991; Speck \& Rowe, 1999; Rowe et al., 2006). Our measurements revealed that sieve tube geometries are more conserved across species, and A. scandens displays radii of sieve elements $(7-13 \mu \mathrm{m})$, which fall within parameters measured in the slender stems of Ipomoea nil (10-20 $\mu \mathrm{m})$ (Knoblauch et al., 2016), or the trunks of canopy dominant trees (6-24 $\mu \mathrm{m})$ (Liesche et al., 2017; Savage et al., 2017). The radii of the sieve tube elements increase basipetally at long distances, as observed in tall trees (Jensen et al., 2012, Savage et al., 2017). Strikingly though, the average sieve plate pore size of $A$. scandens (0.20um radius) was smaller than in stems of other species, and varied little axially. Because pore size is the factor that affects phloem hydraulics the most, A. scandens has high phloem resistance in the stem, compared with other species (Liesche et al., 2017; Savage et al., 2017; Clerx et al., 2020; Barceló-Anguiano et al., 2021a), but within the parameters observed in other Austrobaileyales of the understory (Losada \& Holbrook, 2019). To compensate for the small sieve plate pore size, the secondary phloem of $A$. scandens has an unusually high number of sieve plates along the tangential walls of phloem conduits. Compound sieve plates have been correlated with growth form in height across woody species that reach the forest crowns (Pace et al., 2015; Knoblauch et al., 2016; Liesche et al., 2017; Savage et al., 2017; Losada \& Holbrook, 2019; Clerx et al., 2020; Barceló-Anguiano et al., 2021a,b). Reasons behind the particular phloem morphology of $A$. scandens (lobed arrangement in cross sections, tapered tubes with angled plates and different lengths) may reflect life history traits associated with the liana growth form, such as the imbalance of carbon allocation between the leaf canopy and stem tissues. Thus, a reduced number of below-canopy sink tissues and higher canopy sinks favor a more functional phloem aboveground, whereas in the understory, the mechanics of twining constrains the morpho-functional aspects of phloem (for example, the length of the sieve tubes).

\subsection{Vascular scaling in leaves of Austrobaileyales and other angiosperms}

Within leaves of $A$. scandens, the geometry of vascular elements (tracheids and sieve tube elements) vary across vein orders. Hierarchical scaling of the xylem has been documented in the reticulate leaves of angiosperms, suggesting that the efficiency of water distribution across the continuous xylem conduits follows laws of energy conservation, such as Murray's law (Murray, 1926; McCulloh et al., 2003; Carvalho et al., 2017a, Scoffoni et al., 2017). In contrast, the scaling of sieve tube elements in leaf veins of woody plants remains poorly characterized. Recent work in leaves with different branching patterns, such as the dichotomously branched veins of Ginkgo (Carvalho et al., 2017b), or reticulate-veined leaves of Populus andIllicium (Carvalho et al., 2017a; Losada \& Holbrook, 2019), strongly suggest universal variation of the geometry of 
phloem conduits across leaf vein orders. Yet, an unexplored feature in the leaves of angiosperms is the size of pores connecting sieve tubes in the leaves. Our work provides evidence that pore sizes vary in accordance with sieve tube dimensions, from $0.08 \mu \mathrm{m}$ in minor veins to $0.12 \mu \mathrm{m}$ in the petiole. As a result, variation of both the geometry of tubes and size of pores enhance bulk export of photoassimilates toward the petiole under the pressure-flow predictions (Münch, 1930).

We further report a 1:1.25 xylem to phloem ratio of areas of the major vein in Austrobaileya leaves, balanced in favor of the phloem compared to the general range of 1:4 to 1:10 reported in leaves of deciduous trees (Artschwager, 1926; Waisel et al., 1966). Additionally, the isodiametric sieve tube elements in the midrib linearly increased in number toward the petiole. The dimensions of sieve elements in the major leaf veins remains poorly explored in angiosperms, but they are well documented in the single veined needles of conifers (Ronellenfitsch et al., 2015), in which photo assimilate export is favored by the increasing number of isodiametric phloem conduits from the tip to the base of the needles. This suggests a convergent strategy between conifer needles and $A$. scandens midrib, but whether this is well-maintained in other angiosperm leaves, needs further testing. Furthermore, the isodiametric tracheids of the midrib linearly increased in number toward the petiole, supporting predictions on the uniformity of xylem conduit diameter within the same vein order (McCulloh et al., 2003, 2009; Gleason et al., 2018). Among the scarce studies documenting xylem allometry in single veins, variation in conduit diameter along the midrib has been studied in Fraxinus (Petit et al., 2016) and Acer (Lechthaler et al., 2019). The shortening of tracheids toward the petiole of $A$. scandens suggests that conductivity of water uptake by leaves is lower, in sharp contrast with the highly conductive stems, pointing to hydraulic segmentation of the xylem between the stems and the leaves. In contrast, the sieve tube elements of the petiole reduced their length, but not their diameter, thus maintaining a stable transport capacity. We previously showed a similar trait in the leaves of Illicium parviflorum (Losada \& Holbrook, 2019; Carvalho et al., 2018), a pattern confirmed in leaves of five tree species: Acer saccharum , Liriodendron tulipifera ,Catalpa speciosa, Liquidambar styraciflua, and Quercus rubra (unpublished).

The special characteristics of the petioles have been previously put forward in a number of species such as in the genera Beta (Geiger et al, 1969), Cyclamen (Grimm et al., 1997), or Pelargonium (Ray \& Jones, 2018), suggesting architectural plasticity that is uncoupled from the leaf lamina. Strikingly, we found that the petiole of $A$. scandens is fiberless, in sharp contrast with the massive presence of perivascular fibers in the leaf lamina. Fiberless petioles were further observed in Illicium parviflorum(Losada \& Holbrook, 2019), and suggest that these short petioles require flexibility, especially in understory plants such as the majority of members of the Austrobaileyales, which need to orientate their leaves toward sun flecks. In addition, the petioles of $A$. scandens may aid with twining, as previously suggested (Feild et al., 2003b), in agreement with previous evidence of a pivotal role of petiole reorientation in generating the squeezing force that stabilize twining stems (Isnard et al., 2009).

\subsection{Contrasting vascular strategies between leaves and stems of lianas in the understory}

Our measurements, although limited in number, suggest that the velocity of the phloem in A. scandens is one order of magnitude slower than Ipomoea and in trees (Windt et al., 2006; Babst et al., 2013; Knoblauch et al., 2016), but similar to the rates observed inIllicium parviflorum (Losada \& Holbrook, 2019). While the radii of the phloem conduits were similar in petioles and searcher branches, the hydraulic resistance from leaves to stems followed a continuum, differing by three orders of magnitude from the minor veins to the base of the plants. Yet, this is a smaller difference than that reported between the top and the bottom of tree stems of comparable heights (Savage et al., 2017). Our calculations, which assume a constant viscosity of $1.7 \mathrm{mPa} \mathrm{s}^{-1}$, would not allow transport at long distances with faster velocities. For example, the pressure required to transport the sap $3 \mathrm{~m}$ from the leaves would be $1.4 \mathrm{MPa}$, suggesting that longer distances could impair transport. In conclusion, with constant viscosity and velocity, the export of carbohydrates from the leaves is facilitated by the geometry of the phloem, but encounter architectural limitations in the stems (i.e. tiny pores). What this may imply is that the export of photoassimilates may easily be redirected toward the continuously growing canopy. This is possible because the stem girth is maintained constant for long distances, but enlarges typically at the base of the vine. Additionally, the stems of $A$. scandens are 
photosynthetic along their length, pointing to the possibility of self-sustaining, at least partially, the limited secondary growth, and root elongation.

The vesselless leaves of $A$. scandens were previously suggested as having a simpler anatomy than other angiosperms, such as the absence of palisade parenchyma, low stomatal density with slow responses to VPD changes (Feild et al., 2003), which correlated with a physiology associated to the understory environment (Brodribb \& Feild, 2010). Similarly, woody members of the ancestral ANA grade, such as Amborella trichopoda , is vessel free and lacks reaction wood. (Feild et al., 2005; 2012). Altogether, these results that include a strong hydraulic segmentation of the xylem, and a high resistance of phloem to sap transport, correlate with the slow growth rate of this species in the understory conditions (Feild et al., 2012).

Exploring the phloem of extant members of the ancestral angiosperm grade ANA (Amborellales, Nymphaeales, Austrobaileyales) is particularly relevant, given that fossils, when available, rarely preserve this tissue. Thus, living members allow for the inference of the varied hydraulic solutions evolved -and perhaps maintained- by angiosperms during their initial radiation. A. scandens, the only extant member of the Austrobaileyaceae family, itself one of the three lineages composing the ANA grade, a sister grade to all flowering plants (Mathews \& Donoghue, 1999; Parkinson et al., 1999; Qiu et al., 2000; Soltis et al., 1999, 2018), has been historically used to speculate on the primitive growth habits of the first angiosperms. In particular, one of the critical questions is when and how flowering plants reached the canopy (Judd et al., 2018). Our work provides the first empirical interpretation of long distance transport in woody lianas with simple body plans, and the constraints associated with their life histories. Woody lianas, semi climbers and shrubs (rarely trees) dominate the extant forms of the earliest angiosperm lineages Amborellales and Austrobaileyales. Woodiness, considered the symplesiomorphic condition of angiosperms as a whole, was likely required to colonize the vertical niche during the Cretaceous, previously dominated through millions of years by gymnosperms. The question remains as to whether the great anatomical diversity of climbers, typically considered as highly derived, could have been the ancestral condition of angiosperms.

\section{Acknowledgements:}

We are grateful to William E. (Ned) Friedman for kindly sharing plant material and lab facilities and to the staff of the Arnold Arboretum of Harvard University for continuous support. This work was funded by the National Science Foundation IOS 1456845 research grant to N.M.H. Z.H. was awarded with a research internship program from the DaRin Butz Foundation at the Arnold Arboretum of Harvard University. JML is a ComFuturo researcher at the IHSM La Mayora, funded by FGCSIC, a RTI2018-102222-A-I00 grant from the Spanish Ministry of Science and Universities, and a LINKB20067 from CSIC.

\section{Conflict of interest}

The authors declare there is no conflict of interest.

\section{Data availability}

Data are available upon request to the corresponding author.

\section{References:}

Artschwager, E. (1926). Anatomy of the vegetative organs of the sugar beet. Journal of Agricultural Research , 33, $143-176$.

Babst, B. A., Karve, A. A., \& Judt, T. (2013). Radio-metabolite analysis of carbon-11 biochemical partitioning to non-structural carbohydrates for integrated metabolism and transport studies. Plant $E^{3}$ Cell Physiology, 54, 1016-1025.

Bailey, I. W., \& Swamy, B. G. L. (1949). The morphology and relationships of Austrobaileya . Journal of the Arnold Arboretum, 30, 211-226.

Baillaud, L. (1962). Les mouvements d'exploration et d'enroulement des plantes volubiles. Handb Pflanzenphysiologie , 17, 635-715. 
Barral, A., Gomez, B., Feild, T. S., Coiffard, C \& Daviero-Gomez, V. (2013). Leaf architecture and ecophysiology of an early basal eudicot from the Early Cretaceous of Spain. Botanical Journal of the Linnean Society, 173, 594-605.

Barceló-Anguiano, M., Holbrook, N. M., Hormaza, J. I., \& Losada, J. M. (2021a). Changes in ploidy affect vascular allometry and hydraulic function in Mangifera indica tres. The Plant Journal,https://doi.org/10.1111/tpj.15460.

Barceló-Anguiano, M., Hormaza, J. I., \& Losada, J. M. (2021b). Conductivity of the phloem in mango (Mangifera indica L.) Horticulcture Research,https://doi.org/10.1038/s41438-021-00584-1

Behnke, H. (1986). Sieve element characters and the systematic position of Austrobaileya , Austrobaileyaceae - with comments to the distinction and definition of sieve cells and sieve-tube members.Plant Systematics and Evolution, 152, 101-121.

Brodribb, T. J., \& Field, T. S. (2010). Leaf hydraulic evolution led a surge in leaf photosynthetic capacity during early angiosperm diversification. Ecology Letters 13, 175-183.

Carlquist S. (1991). Anatomy of vine and liana stems: a review and synthesis. In:Putz FE, Mooney HA, eds. The biology of vines . Cambridge: Cambridge University Press, 53-71.

Carlquist, S. (2001). Observations on the vegetative anatomy of Austrobaileya: habitat, organographic and phylogenetic conclusions.Botanical Journal of the Linnean Society , 135 (1), 1-11.

Carvalho, M. R., Losada, J. M., \& Niklas, K. J. (2018). Phloem networks in leaves. Current Opinion in Plant Biology, 43, 29-35.

Carvalho, M. R., Turgeon, R., Owens, T., \& Niklas, K. J. (2017a). The hydraulic architecture of Ginkgo leaves. American Journal of Botany, 104, 1285-1298.

Carvalho, M. R., Turgeon, R. Owens, T., \& Niklas, K. J. (2017b). The scaling of the hydraulic architecture in poplar leaves. New Phytologist, 214, 145-157.

Chen, Y. J., Bongers, F., Zhang, J. L., Liu, J. Y. \& Cao, K. F. (2014). Different biomechanical design and ecophysiological strategies in juveniles of two liana species with contrasting growth habit. American journal of botany , 101 (6), 925-934.

Chery, J. G., Pace, M. R., Acevedo-Rodríguez, P., Specht, C. D. \& Rothfels, C. J. (2020). Modifications during early plant development promote the evolution of nature's most complex woods. Current Biology , 30(2), 237-244.

Clerx, L. E., Rockwell, F. E., Savage, J. A., \& Holbrook, N. M. (2020) Ontogenetic scaling of phloem sieve tube anatomy and hydraulic resistance with tree height in Quercus rubra. American Journal of Botany, $107,852-863$.

Darwin C. (1875). On the movements and habits of climbing plants . John Murray, London: Longman, Green.

Ewers, F. W., Fisher, J. B., \& Fichtner, K. (1991). Water flux and xylem structure in vines. In: Putz FE, Mooney HA, eds. The biology of vines . Cambridge: Cambridge University Press, 127-179.

Feild, T. S., Arens, N. C. \& Dawson, T. E. (2003a). The ancestral ecology of angiosperms: emerging perspectives from extant basal lineages. International Journal of Plant Sciences, 164, 129-142.

Feild, T. S., \& Arens, N. C. (2005). Form, function and environments of the early angiosperms: merging extant phylogeny and ecophysiology with fossils. New Phytologist, 166(2), 383-408.

Feild, T. S., \& Arens, N. C. (2007). The ecophysiology of early angiosperms. Plant, Cell \& Environment, 30, 291-309. 
Feild, T. S., Franks, P. J. \& Sage, T. L. (2003a). Ecophysiological shade adaptation in the basal angiosperm, Austrobaileya scandens(Austrobaileyaceae). International Journal of Plant Sciences,164, 313-324.

Field, T. S., Arens, N. C., \& Dawson, T. E. (2003b). The ancestral ecology of angiosperms: emerging perspectives from extant basal lineages. International Journal of Plant Sciences, 164(S3), S129-S142.

Feild, T. S., \& Wilson, J. P. (2012). Evolutionary voyage of angiosperm vessel structure-function and its significance for early angiosperm success. International Journal of Plant Sciences, 173, 596-609.

Fisher, J. B., \& Blanco, M. A. (2014). Gelatinous fibers and variant secondary growth related to stem undulation and contraction in a monkey ladder vine, Bauhinia glabra (Fabaceae). American Journal of Botany, 101, 608-616.

Geiger, D. R., Saunders M. A., \& Cataldo D. A. (1969). Translocation and accumulation of translocate in the sugar beet petiole. Plant Physiology, 44, 1657-1665.

Gentry, A. G. (1991). The distribution and evolution of climbing plants. In: Putz FE, Mooney HA, eds. The biology of vines . Cambridge, UK: Cambridge University Press, 3-52.

Gerwing, J. J, Farias, D. L. (2000). Integrating liana abundance and forest stature into an estimate of total aboveground biomass for an eastern Amazonian forest. Journal of Tropical Ecology , 16(3), 327-335.

Gleason, S., Blackman, C. J., Gleason, S. T., McCulloh, K. A., Ocheltree, T. W., \& Westoby, M. (2018). Vessel scaling in evergreen angiosperm leaves conforms with Murray's law and area-filling assumptions: implications for plant size, leaf size and cold tolerance.New Phytologist, 218, 1360-1370.

Grimm, E., Jahnke, S., \& Rothe, K. (1997). Photoassimilate translocation in the petiole of Cyclamen and Primula is independent of lateral retrieval. Journal of Experimental Botany,48, 1087-1094.

Hughes, J., \& McCully, M. E. (1975) The use of an optical brightener in the study of plant structure. Stain Technology , 50, 319-329.

Isnard, S., Cobb, A. R., Holbrook, N. M., Zwieniecki, M., \& Dumais, J. (2009). Tensioning the helix: A mechanism for force generation in twining plants. Proceedings of the Royal Society B: Biological Sciences, 276(1667), 2643-2650.

Isnard, S., Speck, T., Rowe, N. P. (2003). Mechanical architecture and development in Clematis : implications for canalised evolution of growth forms. New Phytologist , 158(3), 543-559.

Isnard, S., \& Silk, W. K. (2009). Moving with climbing plants from Charles Darwin's time into the 21st century. American Journal of Botany , 96, 1205-1221.

Jensen, K. H., Lee, J., Bohr, T., Bruus, H., Holbrook, N. M. \& Zwieniecki, M. A. (2011). Optimality of the Münch mechanism for translocation of sugars in plants. Journal of the Royal Society Interface, 8, 1155-1165.

Jensen, K. H., Liesche, J., Bohr, T., \& Schulz, A. (2012a). Universality of phloem transport in seed plants. Plant, Cell \& Environment, 35, 1065-1076.

Jensen, K. H., Mullendore, D. L., Holbrook, N. M., Bohr, T., Knoblauch, M., \& Bruus, H. (2012b). Modeling the hydrodynamics of phloem sieve plates. Frontiers in Plant Science, 3, 151.

Jud, N. A., Michael, D. D., Williams, S. A., Mathews, J. C., Tremaine, K. M., \& Bhattacharya, J. (2018). A new fossil assemblage shows that large angiosperm trees grew in North America by the Turonian (Late Cretaceous). Science advances , 4(9), eaar8568.

Knoblauch, M., Knoblauch, J., Mullendore, D. L., Savage, J. A., Babst, B. A., Beecher, S. D., A.C. Dodgen, Jensen, K. H., \& Holbrook, N. M. (2016). Testing the Münch hypothesis of long distance phloem transport in plants. eLife 5 . 
Knoblauch, M., Vendrell, M., de Leau, E., Paterlini, A., Knox, K., Ross-Elliot, T., Reinders, A. Brockman, S. A., Ward J., \& Oparka, K. (2015). Multispectral phloem-mobile probes: properties and applications.Plant Physiology, 167, 211-1220.

Lechthaler, S., Colangeli, P., Gazzabin, M., \& Anfodillo, T. (2019). Axial anatomy of the leaf midrib provides new insights into the hydraulic architecture and cavitation patterns of Acer pseudoplatanus leaves. Journal of Experimental Botany, 70, 6195-6201.

Liesche, J. (2017). Sucrose transporters and plasmodesmal regulation in passive phloem loading. Journal of Integrative Plant Biology, 59, 311-321.

Liesche, J., Pace, M.R., Xu, Q., Li, Y., \& Chen, S. (2017). Height-related scaling of phloem anatomy and the evolution of sieve element end wall types in woody plants. New Phytologist, 214, 245-256.

Linskens, H. F., \& Esser, K. L. (1957). uber eine spezifische anfarbung der pollenschlauche im griffel und die zahl der kallosepfropfen nach selbstungund fremdung. Naturwissenschaften, 44, 16-16.

Losada, J. M., \& Holbrook, N. M. (2019). Scaling of phloem hydraulic resistance in stems and leaves of the understory angiosperm shrubIllicium parviflorum . American Journal of Botany, 106, 244-259.

Mathews, S., \& Donoghue, M. J. (1999). The root of angiosperm phylogeny inferred from duplicate phytochrome genes. Science, 286, 947-950.

Metcalfe, C. R. (1987). Anatomy of the dicotyledons . Ed. 2, Volume III. Magnoliales, Illiciales, and Laurales. Oxford: Clarendon Press.

McCulloh, K. A., Sperry, J. S., \& Adler, F.R. (2003). Water transport in plants obeys Murray's law. Nature, 421, 939-942.

McCulloh, K. A., Sperry, J. S., Meinzer, F. C., Lachenbruch, B., \& Atala, C. (2009). Murray's law, the 'Yarrum'optimum, and the hydraulic architecture of compound leaves. New Phytologist 184(1), 234-244.

Moya, R., Gondaliya, A. D., \& Rajput, K. S. (2017). Stem anatomy and development of interxylary phloem in Strychnos bredemeyeri(Loganiaceae). Anales de Biologia, 39.

Mullendore, D. L., Windt, C.W., Van As, H., \& Knoblauch, M. (2010). Sieve tube geometry in relation to phloem flow. Plant Cell, 22, 579-593.

Munch, E. (1930). Die stroffbewegungen in der pflanze. Jena, G. Fischer, Germany.

Pace, M. R., Alcantara, S., Lohmann, L.G., \& Angyalossy, V. (2015). Secondary phloem diversity and evolution in Bignonieae (Bignoniaceae).Annals of Botany, 116, 333-358.

Pace, M. R., Lohmann, L.G. \& Angyalossy, V. (2011). Evolution of disparity between the regular and variant phloem in Bignonieae (Bignoniaceae). American Journal of Botany 98, 602-618.

Pace, M. R., Acevedo-Rodriguez, P., Amorim, A. M. \& Angyalossy, V. (2018). Ontogeny, structure and occurrence of interxylary cambia in Malpighiaceae. Flora , 241, 46-60.

Parkinson, C. L., Adams, K.L. \& Palmer, J. D. (1999). Multigene analyses identify the three earliest lineages of extant flowering plants. Current Biology 9, 1485-1491.

Petit, G., Savi, T., Consolini, M., Anfodillo, T., \& Nardini, A. (2016). Interplay of growth rate and xylem plasticity for optimal coordination of carbon and hydraulic economies in Fraxinus ornus trees. Tree Physiology , 36(11), 1310-1319.

Putz, F. E., Holbrook, N. M. (1992). Biomechanical studies of vines . In: The Biology of Vines. Cambridge University Press, Cambridge, UK, 73-99. 
Qiu, Y. L., Lee, J., Bernasconi-Quadroni, F., Soltis, D. E., Soltis, P. M., Zanis, M., Zimmer, E. A., Chen, Z., Savolainen, V., \& Chase, M. W. (2000). Phylogeny of basal angiosperms: analyses of five genes from three genomes. International Journal of Plant Sciences, 161, 3-27.

Ray, D. M., \& Jones, C.S. (2018). Scaling relationships and vessel packing in petioles. American Journal of Botany, 105, 667-676.

Ray, D. M. \& Savage, J. A. (2020). Immunodetection of cell wall pectin galactan opens up new avenues for phloem research. Plant Physiology , 183(4), 1435-1437.

Robertson, A. G., Jang, H. F. \& Seth, R.S. (1992). Three-dimensional visualization of confocal images of wood pulp fibres. Journal of Materials Science Letters 11, 1416-1418.

Ronellenfitsch, H., Liesche, J., Jensen, K. H., Holbrook, N.M., Schulz, A., \& Katifori, E. (2015). Scaling of phloem structure and optimality of photoassimilate transport in conifer needles. Proceedings of the Royal Society, B, Biological Sciences 282, 20141863.

Rowe, N. P., Isnard, S., Gallenuller, F., Speck, T. (2006). Diversity of mechanical architectures in climbing plants: an ecological perspective. In: Herrel A, Speck T, Rowe NP, eds. Ecology and biomechanics: a mechanical approach to the ecology of animals and plants. Boca Raton, FL, USA: Taylor and Francis, $35-59$.

Savage, J. A., Beecher, S., Clerx, L., Gersony, J.T., Knoblauch, J., Losada, J. M., Jensen, K.H., Knoblauch, M., \& Holbrook, N. M. (2017). Maintenance of carbohydrate transport in tall trees. Nature Plants 3: 965.

Schnitzer, S. A., Mangan, S. A., Dalling, J. W., Baldeck, C. A., Hubbell, S. P., Ledo, A., Muller-Landau, H., Tobin, M. F., Aguilar, S., Brassfield, D., Hernandez, A., Lao, S., Perez, R., Valdes, O., \& Rutishauser Yorke, S. (2012). Liana abundance, diversity, and distribution on Barro Colorado Island, Panama. PloS one $7(12)$, e52114.

Scoffoni, C., Albuquerque, C., Brodersen, C., Townes, S. V., John, G. P., Cochard, H., Buckley, T., McElrone, A. J., \& Sack, L.(2017). Leaf vein xylem conduit diameter influences susceptibility to embolism and hydraulic decline. New Phytologist, 213(3), 1076-1092.

Silk, W. K., \& Holbrook, N. M. (2005). The importance of frictional interactions in maintaining the stability of the twining habit.American Journal of Botany, 92(11), 1820-1826.

Speck T., \& Rowe, N. P. (1999). A quantitative approach for analytically defining size, growth form, and habit in living and fossil plants. In: Kurmann MH, Hemsley AR, eds. The evolution of plant architecture . Kew, UK: Royal Botanic Gardens, 447-479.

Srivastava, L. M. (1970). The secondary phloem of Austrobaileya scandens . Canadian Journal of Botany , 48(2), 341-359.

Soltis, D. E.., Soltis, P. S., Endress, P., Chase, M. W., Manchester, S., Judd, W., Majure, L., \& Mavrodiev, E. (2018). Phylogeny and evolution of the angiosperms: revised and updated edition. University Press, Chicago, USA.

Soltis, P. S., Soltis, D. E, \& Chase, M. W. (1999). Angiosperm phylogeny inferred from multiple genes as a tool for comparative biology. Nature, 402, 402-404.

Torode, T. A., O’Neill, R., Marcus, S. E., Cornuault, V., Pose, S, Lauder, R. P., Kračun, S. K., Rydahl, M. G., Andersen, M. C. F., Willats, W., Braybrook, S., Townsend, B.J., Clausen, ;. H., \& Knox, P. (2018). Branched pectic galactan in phloem-sieve-element cell walls: implications for cell mechanics. Plant Physiology 176(2), 1547-1558.

Waisel, Y., Ilana, N., Fahn, A. (1966). Cambial activity inEucalyptus camaldulensis Dehn. II. The production of phloem and xylem elements. New Phytologist , 65(3), 319-324. 
Windt, C. W., Vergeldt, F. J., De Jager, P. A., Van As, H. (2006). MRI of long-distance water transport: a comparison of the phloem and xylem flow characteristics and dynamics in poplar, castor bean, tomato and tobacco. Plant, Cell \& Environment, 29, 1715-1729.

Wyka, T. P., Oleksyn, J., Karolewski, P., \& Schnitzer, S. A. (2013). Phenotypic correlates of the lianescent growth form: a review. Annals of Botany, 112, 1667-1681.

\section{FIGURES AND LEGENDS}

FIGURE 1. (A) Adult vines of Austrobaileya scandens in the greenhouse. (B ) A. scandens vines at the canopy layer in the tropical rainforest of Queensland (Australia). (C) Apical part of a 'searcher' branch in the greenhouse. (D) Branches twisted around a stable support without increasing their diameter. (E ) The average leaf area at each particular node increased by five fold up to the fully expanded leaves of the seventh node $(p<0.05)$.

FIGURE 2. Vascular anatomy of the continuum petiole-mid vein of Austrobaileya scandens leaves. (A ) Mature leaf of $A$. scandens . (B ) Vascular tissues of the fiber less petiole. (C) Vasculature in the mid part of the major vein showing a massive layer of pericyclic fibers surrounding the xylem and the phloem. (D) Vasculature at the tip of the mid vein. (E ) Cross sectional areas of the vascular tissues at the three positions in the midvein: while the cross-sectional areas of xylem (red squares) and phloem (yellow circles) decreased linearly toward the tip $(p<0.05)$, the fibers (grey ribbons) occupied a wide cross-sectional area in the leaf lamina, but not in the petiole.B-D . Cross sections stained with aniline blue to detect callose of the sieve tube elements. Scale bars: $\mathbf{A}=1 \mathrm{~cm} ; \mathbf{B}-\mathbf{D}=200 \mu \mathrm{m}$.

FIGURE 3. Geometrical scaling of the vascular elements in the leaves of Austrobaileya scandens . (A ) General view of the leaf veins showing the sampling areas (pink hexagons) and closeup of the minor veins. (B-C ) Length (squares) and radius (circles) of the individual vessel elements (red), and sieve tube elements (yellow) across vein orders; error bars represent standard error at a $p<0.05$. Inset in panel (A) shows a fluorescence image section of the leaf stained with the Feulgen reactive, cleared, and cuticle dissected. Fou, fourth order veins; pet, petiole; pri, primary vein; sec, secondary vein; ter, tertiary vein. Scale bar $=500 \mu \mathrm{m}$.

FIGURE 4. Velocity of the phloem sap in Austrobaileya scandens leaves. Time-lapse images of a secondary vein showing a 2 min advancement of esculin hydrate dye from $0 \mathrm{~min}(\mathbf{A})$ to $6 \mathrm{~min}(\mathbf{D})$. Insets show the thresholding applied to the sequential images for the calculation of velocity, with a gradual accumulation of the dye within the veins. Scale bars $=1000 \mu \mathrm{m}$.

FIGURE 5. Anatomy of the Austrobaileya scandens stems. (A ) Cross section of a $2 \mathrm{~mm}$ diameter 'searcher' branch tip with primary growth, with an extensive central pith. (B ) Same stem showing callose in the continuous phloem ring (fluorescent green). (C) Cross section of a stiff $2 \mathrm{~mm}$ diameter branch showing a dramatic increase in lignification of the pith, the xylem, and a pericyclic fiber cap (fluorescent green). (D ) The phloem forms a thin layer between the xylem and the fiber cap. (E ) Wider stems (8mm diameter) with a high degree of lignification in all central tissues, wide vessels of the xylem, and enlarged areas between the xylem and the fiber cap. (F ) The fascicular phloem tissue was separated by axial multilayered phloem parenchyma and the active tubes were in the vicinity of the vascular cambium. A,C,E: cross sections of stems stained with acridine orange, which displays fluorescence of the lignified tissues in fluorescent green and living tissues in reddish color; $\mathbf{B}, \mathbf{D}, \mathbf{F}$ : cross sections of the stems stained with aniline blue for callose in the sieve tube elements of the phloem. F, fibers; p, pith; phl, phloem; xyl, xylem. Scale bars:A-F $=1 \mathrm{~mm}$; insets $=100 \mu \mathrm{m}$.

FIGURE 6. Immunolocalization of LM26 epitope in the sieve tube elements of searcher branches of Austrobaileya scandens. (A) Transverse section showing multicellular arrangement in the different tissue layers, including three isolated tracheids that compose the primary xylem (red arrowheads). (B ) Same section displaying the sieve tube elements of the primary phloem forming a continuous ring (yellow arrows). (C) Merged images. (D ) Close up of the phloem in cross section. (E ) The profile of the sieve tubes in cross section after immunolocalization (yellow arrows). (F ) Merged images. (G ) Longitudinal section of 
the branch displaying he external part in the top and the internal tissues at the bottom. (H ) Longitudinal profile of the sieve tube element wall after immunolocalization, yellow arrowheads define the connection between tubes. (I) Merged images. (J) Detail of the sieve tube connections. (K) Sieve plate in the primary sieve tubes are slightly tangential (yellow arrowhead). (L) Merged images. 4um thick transverse (A-F ) or longitudinal (G-L ) sections of the flexible branches displaying autofluorescence with the $405 \mathrm{~nm}$ filter $(\mathbf{A}, \mathbf{D}, \mathbf{G}, \mathbf{J})$, immunolocalized with the LM26 monoclonal antibody (B,E,H,K ), and merged images $(\mathbf{C , F}, \mathbf{I}, \mathbf{L})$. Ct, cortical tissue; phl, phloem; sp, sieve plate; vc, vascular cambium; xyl, xylem. Scale bars:A-C $=50 \mu \mathrm{m} ; \mathbf{G}-\mathbf{I}=25 \mu \mathrm{m} ; \mathbf{D}-\mathbf{F}, \mathbf{J}-\mathbf{L}=10 \mu \mathrm{m}$.

FIGURE 7 . Morphology of the sieve tube elements in the stems of Austrobaileya scandens . (A ) Longitudinal view of a sieve tube element from a flexible branch, $2 \mathrm{~mm}$ diameter, showing either simple or compound sieve plate connections (arrows). (B ) Sieve tube element of an $8 \mathrm{~mm}$ diameter stem showing numerous sieve plate connections between tubes (arrows). (C ) Longitudinal view of a sieve tube element with scanning electron microscopy displaying numerous sieve plates and sieve areas all along the tube wall (arrows). (D ) Close ups of three sieve plates (analogous to the white dotted square in figure C), with details of pores. (E ) Sieve tube element length (squares), and width (circles) across axial stems of different diameter ranges; bars represent the standard error at a $p<0.05$.A, B , longitudinal hand sections of the stems stained with aniline blue to detect callose (bright fluorescence); C,D , scanning electron microscopy images showing the sieve plates and the sieve pores in detail. Scale bars: $\mathbf{A}-\mathbf{C}=20 \mathrm{um} ; \mathbf{D}=2 \mu \mathrm{m}$.

FIGURE 8. Sieve tube hydraulic resistance across the aerial organs of Austrobaileya scandens. The sieve tube resistance drops from 1.5 to 2 orders of magnitude from the minor leaf veins (squares) to the base of the stems (circles), even though the distance between them could be up to $20 \mathrm{~m}$. Numbers indicate the relative position along the transport pathway, noted in the figures, but they do not represent real distances.

\section{SUPPORTING INFORMATION}

Figure S1. Pore radii in the leaves of Austrobaileya scandens. X axis displays the different vein orders: pet, petiole; pri, primary vein; sec, secondary vein; ter, terciary vein; fou, fourth vein order; fiv, fifth vein order. Bars represent standard error at a $\mathrm{p}<0.05$. 

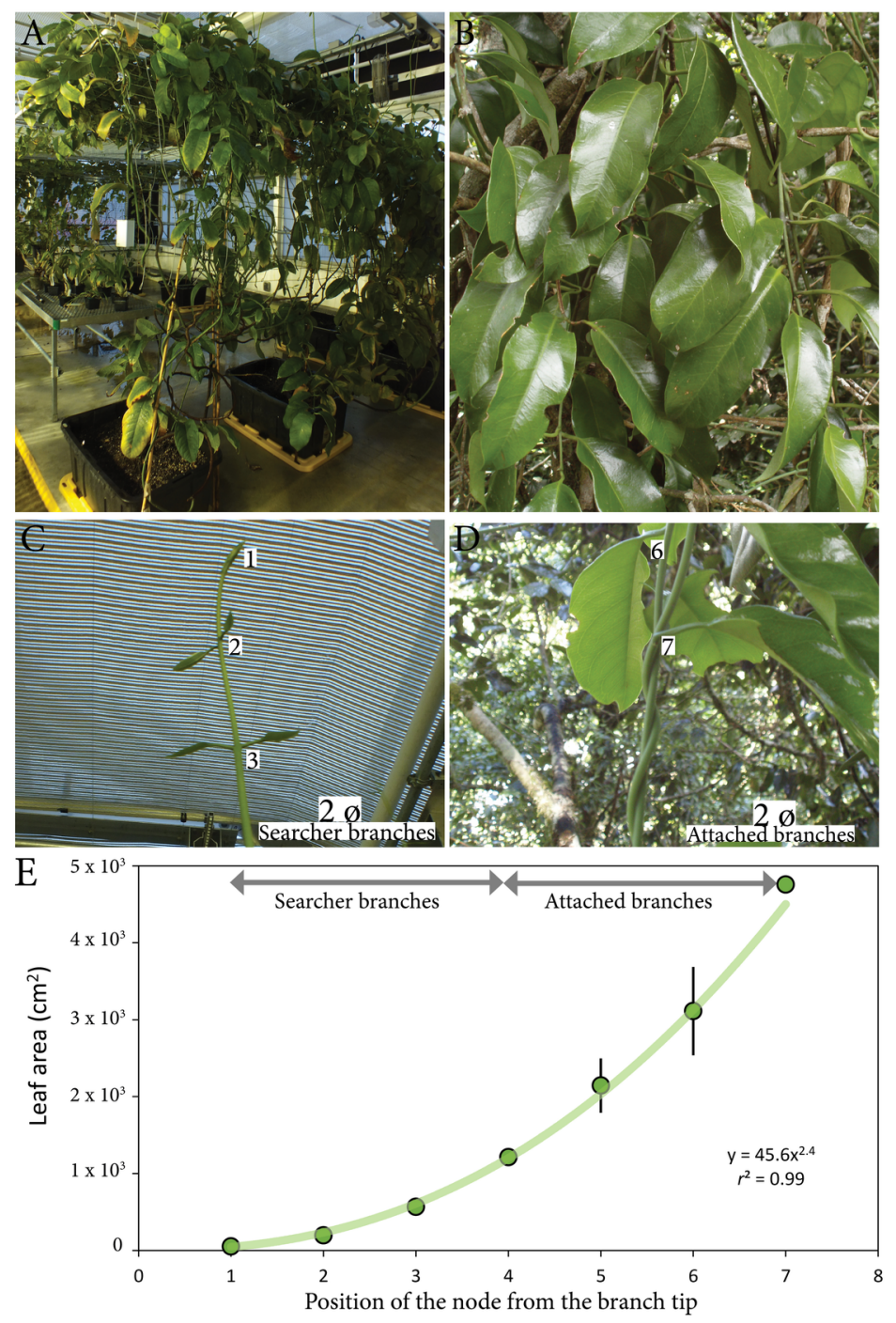


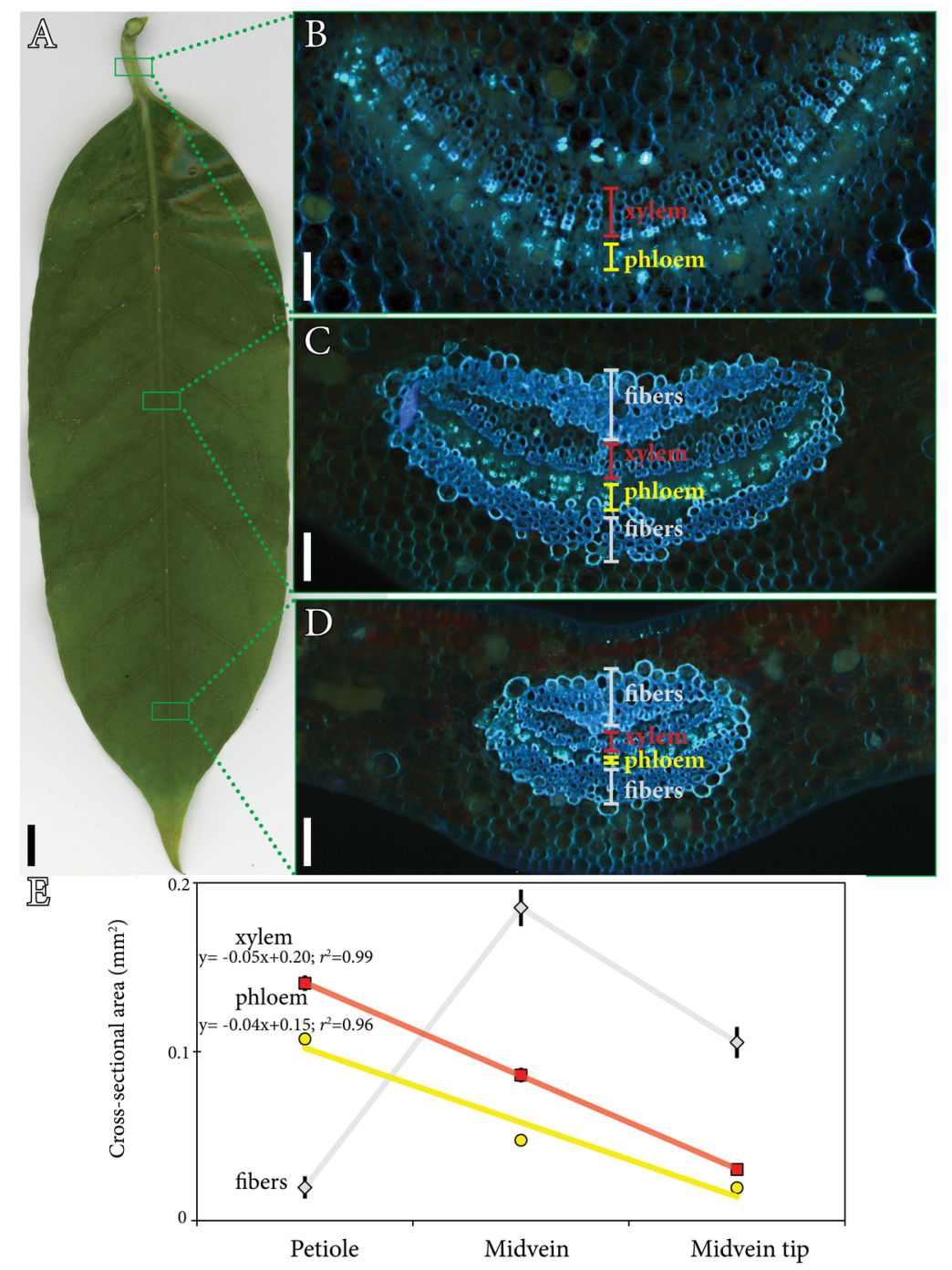




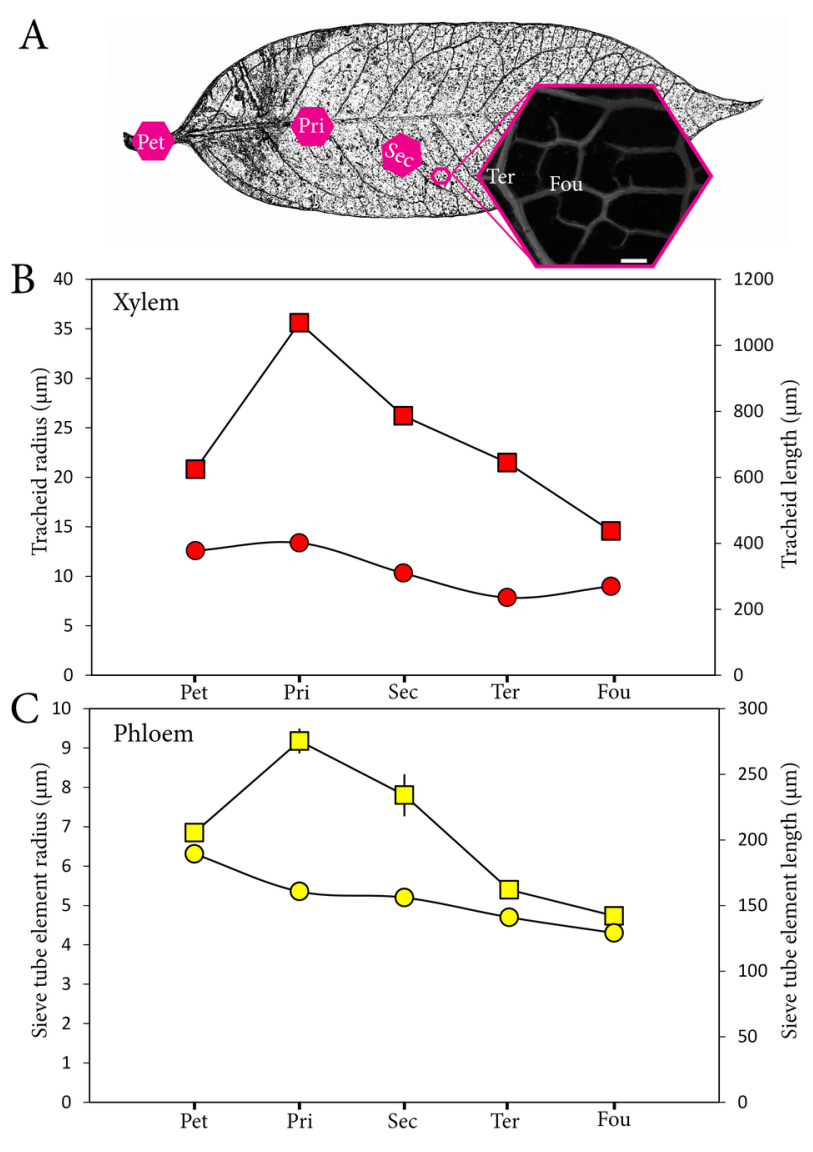




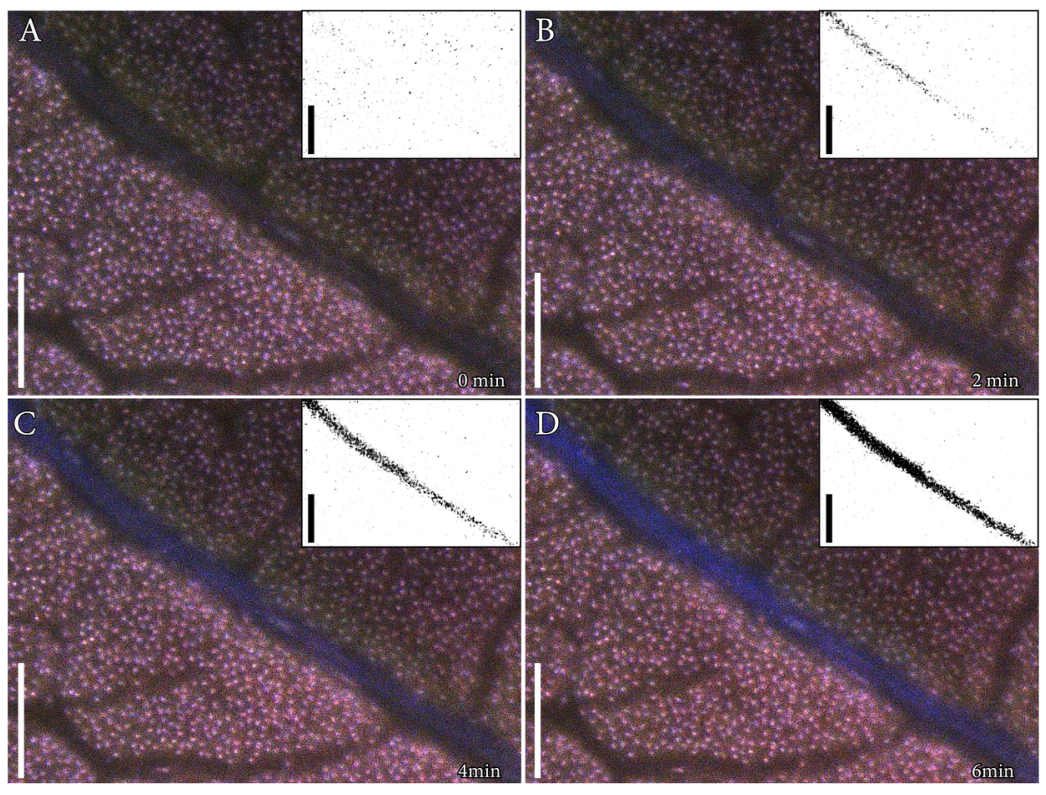




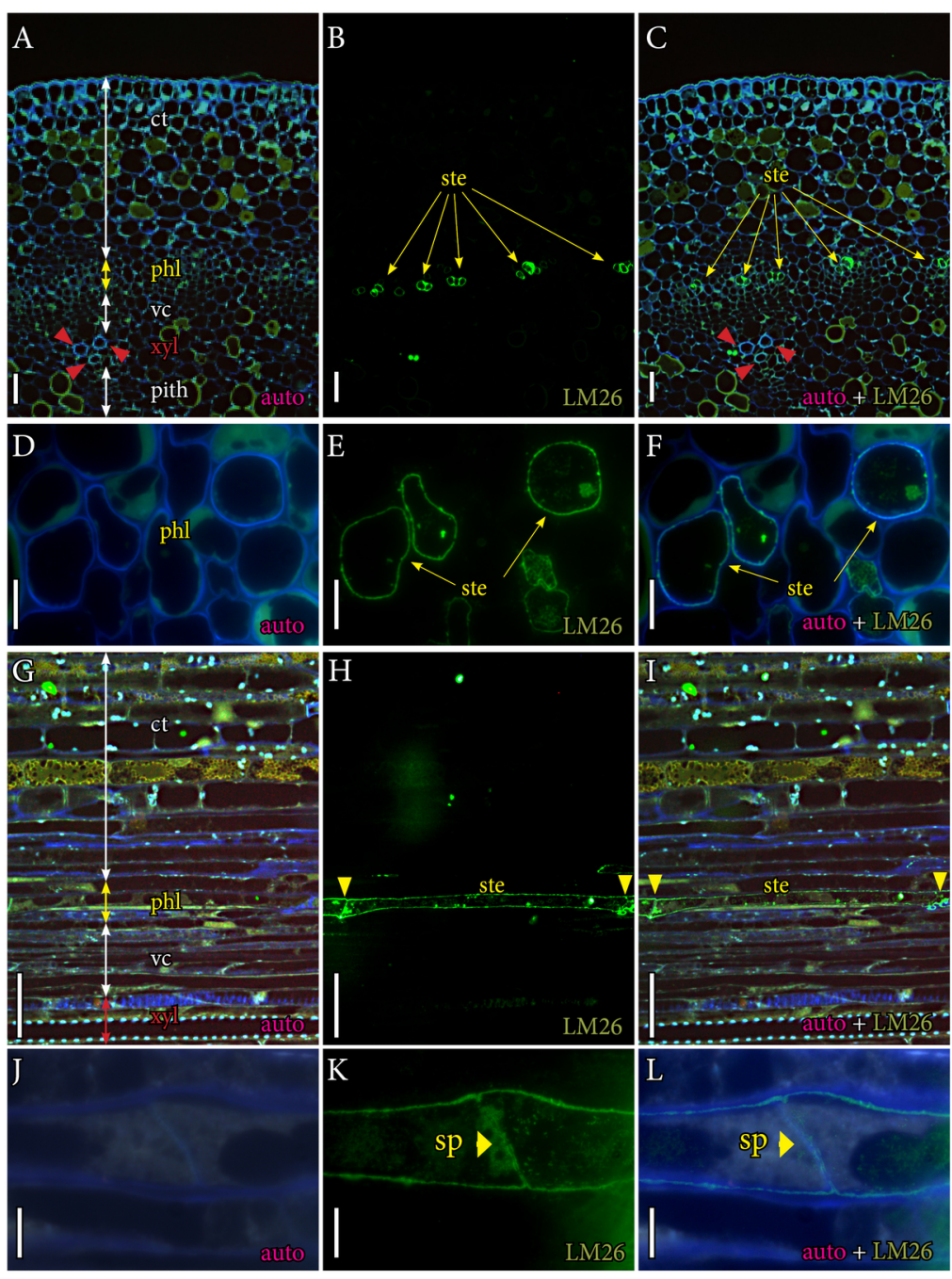




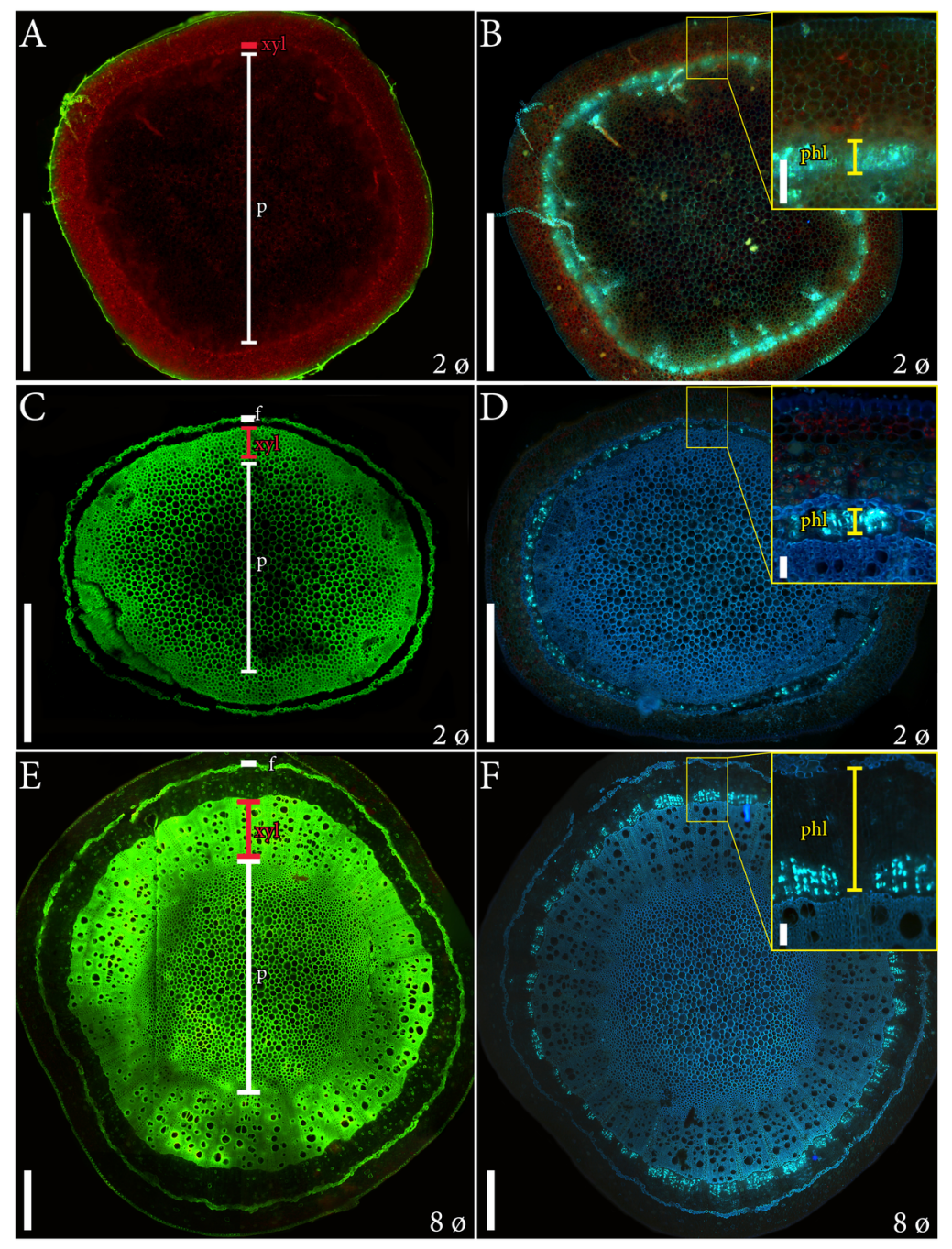




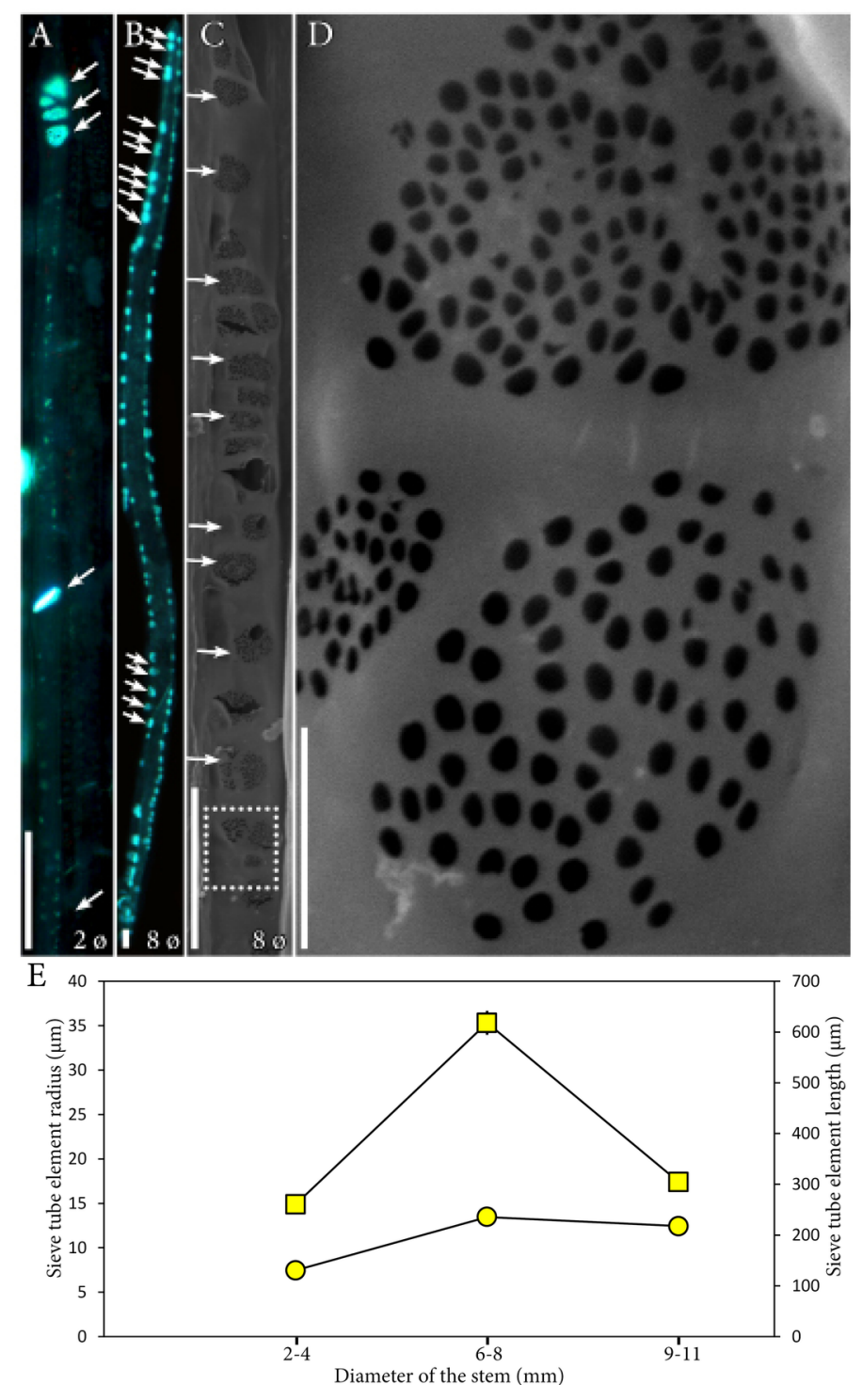




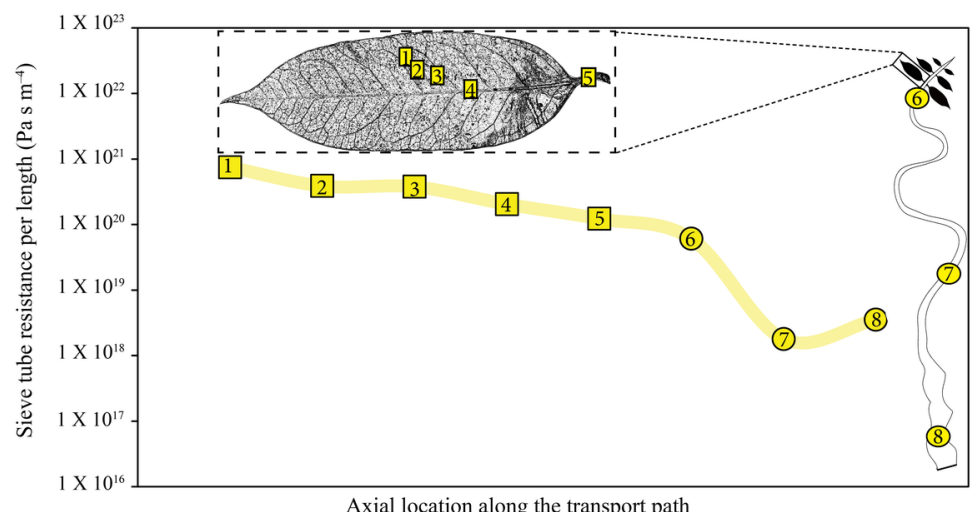

